\title{
The Effect of Thyroid Hormone Replacement on the Level of Blood Pressure in the Cases of Subclinical Hypothyroidism
}

\author{
Sukriti Kumar ${ }^{1}$, Sumit Rungta ${ }^{2}$, Manish Gutch ${ }^{* 3}$, Annesh Bhattacharya ${ }^{4}$, Syed Mohd Razi ${ }^{5}$, Agarwal Avinash ${ }^{6}$
}

\section{Sukriti Kumar ${ }^{1}$, Sumit Rungta ${ }^{2}$, Manish Gutch*3, Annesh Bhattacharya ${ }^{4}$, Syed Mohd Razi ${ }^{5}$, Agarwal Avinash $^{6}$}

\section{'Assistant Professor, Department of Radiodiagnosis, King George's Medical College, Lucknow, Uttar Pradesh, INDIA. ${ }^{2} \mathrm{MD}$ (Medicine), Department of Medi- cine, King George's Medical College, Lucknow, Uttar Pradesh, INDIA. ${ }^{3} \mathrm{MD}$ (Medicine), DM (Endocrinology), Assistant Professor, Department of Medicine, King George's Medical College, Lucknow, Uttar Pradesh, INDIA. ${ }^{4} \mathrm{MD}$ Medicine, Senior Resident, Department of Medicine, King George's Medical College, Lucknow, Uttar Pradesh, INDIA. \\ ${ }^{5} \mathrm{MD}$ (Medicine), DM (Endocrinology), Senior Resident, Department of Endocrinology, LLRM Medical College, Meerut, Uttar Pradesh, INDIA. ${ }^{6} \mathrm{MD}$, Associate Prof, Department of Medicine, KGMU, Lucknow, Uttar Pradesh, INDIA.}

\section{Correspondence Dr Manish Gutch \\ M.D (Medicine), DM (Endocrinology)، Assistant Professor, Department of Medicine, King George's Medical College, Lucknow, Uttar Pradesh, INDIA. Mobile no: 9453429252 \\ Email: manish07gutch@gmail.com \\ History \\ - Submission Date: 16-07-2017 \\ - Revised Date: 17-12-2017 \\ - Accepted Date: 17-12-2017}

DOI : 10.5530/ijmedph.2018.1.5

Article Available online

http://www.ijmedph.org/v8/i1

\section{Copyright}

(C) 2018 Phcog.Net. This is an openaccess article distributed under the terms of the Creative Commons Attribution 4.0 International license.

\begin{abstract}
Background: Hypothyroidism (both subclinical and overt) is associated with increased cardiovascular morbidity. About 3\% hypertensive patients found to have hypothyroidism during the routine investigations. Objectives: To assess the effect of thyroid hormone replacement on the level of blood pressure in the cases of newly diagnosed subclinical hypothyroidism. Methods: Patients above the age of 15 years admitted to various wards (Indoor) or attending Endocrinology OPD at teriatary care health centre of north India were enrolled during the period of one year. The cases were divided into two groups, normotensive and hypertensive. Cases with subclinical hypothyroidism after evaluation were prescribed thyroxine replacement therapy to achieve euthyroid function. Each group followed periodically at 1 1/2, 03 and 06 month with measurement of blood pressure and serum TSH, T3 and T4 level. Results: The prevalence of hypertension in cases of subclinical hypothyroidism in this study was 33.4 per 100 populations. There was no correlation between serum TSH level and blood pressure level in hypertensive group ( $p>0.05$ ). In hypertensive group mean fall in blood pressure after thyroxine replacement therapy was systolic blood pressure $20.10 \pm 11.2$ diastolic blood pressure $13.16 \pm 3.8$ and in mean arterial pressure $15.2 \pm 4$.7. With replacement of thyroxine hormone, the blood pressure was normalized in $47.4 \%$ (45 out of 95 cases) cases with elevated blood pressure. Conclusion: The effect of thyroxine replacement therapy in cases of hypertension with subclinical hypothyroidism on blood pressure was significant reduction in blood pressure after achieving normal thyroid function.

Key words: Subclinical hypothyroidism, Hypertension, Thyroxine replacement.
\end{abstract}

\section{INTRODUCTION}

Hypothyroidism is a condition resulting from a lack of the effects of thyroid hormone on body tissues. Because thyroid hormone affects growth and development and regulates many cellular processes, the absence or deficiency hormone has many detrimental consequences. Iodine deficiency remains the most common cause of hypothyroidism worldwide. In areas of iodine sufficiency, autoimmune disease (Hashimoto's thyroiditis) and iatrogenic causes (treatment of hyperthyroidism) are most common. ${ }^{1,2}$

Subclinical hypothyroidism ( $\mathrm{SCH}$ ) is a common condition affecting $4 \%-20 \%$ of the general population. $\mathrm{SCH}$ is defined as increased serum thyrotropin (TSH) concentrations and normal serum free thyroxine levels (fT4). ${ }^{3}$ Patients with primary hypothyroidism are at a three times greater risk for early atherosclerosis, as shown independently for other risk factors, such as atherogenic lipid profile, hypertension and impaired endothelial function. Whether SCH has influence on the same risk factors and is associated with atherosclerosis is still under debate. Some studies showed that there is an association, ${ }^{4,5}$ but others did not. ${ }^{6}$

Several studies have shown an association between SCH and hypercholesterolemia, ${ }^{13,14}$ but other stud- ies have not. ${ }^{15-18}$ Monzani and cols. ${ }^{19}$ and Nagasaki and cols. ${ }^{20}$ showed increased Carotid Intima-Media Thickness (CIMT) in patients with SCH. Kim and cols. ${ }^{21}$ showed a difference in total cholesterol, LDL-C, and mean CIMT $(0.66 \pm 0.1 \mathrm{~mm}$, vs. $0.57 \pm 0.08 \mathrm{~mm})$ in $\mathrm{SCH}$, compared with healthy control groups. The difference of CIMT in the study of Kim and cols. ${ }^{21}$ is perhaps due to differences in mean cholesterol between the groups.

In the study by Liu et.al ${ }^{23}$ their investigation confirmed that subclinical hypothyroidism could increase the risk for hypertension. These results differ from those of the cross-sectional study ${ }^{22,24}$ in which subclinical hypothyroidism was not associated with an increase in blood pressure.

The prevalence of hypothyroidism is in excess of $2 \%$ in the general population. Although most common age of onset is the 40-60 years of age group, it can occur in both sexes at any age Hypothyroidism (both subclinical and overt) is associated with increased cardiovascular morbidity and the patient with subclinical hypothyroidism if not diagnosed early, have increased possibility of subsequently leading with frank hypothyroidism.?

Cite this article : Kumar S, Rungta S, Gutch M, Bhattacharya A, Razi SM, Avinash A. The Effect of Thyroid Hormone Replacement on the Level of Blood Pressure in the Cases of Subclinical Hypothyroidism. Int J Med Public Health. 2018;8(1):24-28 
Because of these controversies, the benefit from thyroid replacement therapy in SCH is unclear. There are very few studies which show the effect of thyroid hormone replacement on the level of blood pressure in the cases of subclinical hypothyroidism. There is very limited data from the Indian subcontinent.

\section{METHODS}

\section{Subject}

A total of 280 newly diagnosed subclinical hypothyroidism patients were enrolled during the study period of 1 year in tertiary care centre in North-India. To assess the effect of thyroid hormone replacement on the level of blood pressure in the cases of newly diagnosed case of subclinical hypothyroidism.

The criteria for SCH were: normal fT4 (10.3-24.45 pmol/L) and elevated TSH (4.2-10.0 mU/L) serum levels in at least two thyroid function tests measured no less than two weeks apart and for to diagnose hypertensive according to JNC-7 criteria i.e; systolic Blood Pressure $\geq 140 \mathrm{~mm}$ of $\mathrm{Hg}$ or diastolic blood pressure $\geq 90 \mathrm{~mm}$ of $\mathrm{Hg}$. To get an accurate blood pressure measurement, patients were evaluated based on the average of two or more blood pressure readings at three or more office visits. Inclusion criteria: only newly diagnosed cases of subclinical hypothyroidism patients and newly diagnosed cases of subclinical hypothyroidism with newly diagnosed hypertensive patients were enrolled in the study. Patients were excluded if they have clinical hypothyroidism ( TSH $>10$ ), white coat hypertension, antihypertensive therapy in the past, Congenital hypothyroidism, Pregnancy, Sick euthyroid syndrome, Subacute thyroiditis, Drug induced hypothyroidism, secondary hypothyroidism, patient with renal, cardiac illness, other endocrine disorders and severely ill, or taking thyroid replacement therapy, and not giving consent. Indications for the treatment were presence of Anti TPO Antibody, presence of goitre, and menses irregularity in subclinical hypothyroidism patient.

This was a prospective observational study based on a routine medical procedure, and additional written informed medical consent was obtained before the start of study. Ethical committee approval was taken before the start of the study.

METHOD: Measurement of blood pressure was done by mercury sphygmomanometer in right arm in sitting and supine position, the care taken during measurement that the patient to sit quietly for $5 \mathrm{~min}$ before measuring blood pressure, the patient should be seated comfortably with the back supported and the upper arm bared without constrictive clothing, the legs should not be crossed, the arm should be supported at heart level, and the bladder of the cuff should encircle at least $80 \%$ of the arm circumference, larger or smaller cuffs were used as needed. The mercury column would be deflated at 2 to $3 \mathrm{~mm} / \mathrm{sec}$, and the first and last audible sounds would be taken as systolic and diastolic pressure. Thyroid peroxidase antibody (TPOAb): Less than $35 \mathrm{IU} / \mathrm{mL}$.

STUDY PROTOCOL: The cases of subclinical hypothyroidism were divided into two groups, normotensive and the hypertensive. Cases after thorough evaluation were prescribed thyroxine replacement therapy to achieve euthyroid function. Each group followed periodically at $1 \frac{1}{2}, 03$ and 06 month with measurement of blood pressure and serum TSH level and studied for effect of thyroxine replacement on BP level.

\section{Statistical analysis}

Continuous data were summarized as Mean \pm SD while discrete (categorical) in number and percentage. Continuous two independent groups were compared by parametric independent Student's $t$ test and the significance of parametric t test was also validated with nonparametric alternative Mann-Whitney $U$ test, where appropriate. Discrete (categorical) groups were compared by chi-square $\left(\chi^{2}\right)$ test. A two-sided $(\alpha=2)$ p values less than $0.05(\mathrm{p}<0.05)$ was considered statistically significant. All analyses were performed on STATISTICA software (Windows version 6.0).

\section{RESULTS}

The study evaluated the effect of thyroid hormone replacement on the level of blood pressure in the cases of subclinical hypothyroidism at a tertiary care centre. A total of 280 patients were recruited and evaluated after inclusion and exclusion criteria. Figure 1 shows the study protocol.

\section{Baseline Characteristics}

1. DEMOGRAPIC PROFILE: Table 1 showed the age and sex distributions of studied patients. The ages of study subjects ranged between 15 to 80 years with mean ( \pm SD) for males and female was found to be $41.0 \pm 12.8$ and $44.1 \pm 15.3$. Among the patients, mostly were above 40 years of age (53.6\%) and mostly were females (80.4\%).

2. PREVALENCE OF HYPERTENSION: The prevalence of hypertension in cases of subclinical hypothyroidism in this study was 33.9 per 100 populations and its increases with increasing age. In age group $<20$ years prevalence is $0 \%$, in age group $20-40$ years it was $16.7 \%$ and in age group $>40$ years prevalence was $50 \%$ which is statistically significant $\mathrm{p}=0.02$. The male to female ratio was found to be $35(36.8 \%): 60(63.2 \%)$ or 1:1.71 (Table 1). There is positive linear correlation between serum TSH and blood pressure level and which was statistically insignificant $(\mathrm{p}=0.236)$ (Table 2).

\section{II.Cardiovascular Risk Factors Betwwen Normotensive and Hypertensive Group}

Table 3 shows the additional cardiovascular risk factors between normotensive and hypertensive groups: male sex, advance age, smoking, family history of hypertension and weight were found to be statistically significant between the two groups however BMI and history of diabetes were found to be non significant between the groups.

\section{Effect of thyroxine replacement on systolic, diastolic, mean and on weight reduction:}

In our study, we had found significant reduction of blood pressure on thyroid hormone replacement in hypertensive patient with subclinical hypothyroidism. The mean fall in blood pressure in normotensive patient was in systolic blood pressure, $2.72 \pm 3.2$ diastolic blood pressure $2.45 \pm 4.2$ and in mean arterial pressure $1.97 \pm 3.7$ after thyroxine replacement therapy (Table 4 ) while in cases of hypertension mean fall in blood pressure after thyroxine replacement therapy was in systolic blood pressure $20.1 \pm 11.2$ diastolic blood pressure $13.16 \pm 3.8$ and in mean arterial pressure $15.2 \pm 4.7$ (Table 5). The normalization of blood pressure in cases of hypertension with hypothyroidism with normalization of serum TSH level after thyroxine replacement therapy was significant $(<\mathrm{p}=0.05)$. Normalization of TSH level was noted in all the patients after 6 months of thyroxine replacement therapy. Figure 2 and 3 with replacement of thyroxine hormone, the blood pressure was normalized in $47.4 \%$ (45 out of 95 cases) cases with elevated blood pressure.

\section{DISCUSSION}

The results of our study suggest an association between subclinical hypothyroidism and increased blood pressure levels. The heart is a major target organ for thyroid hormone action and marked change occur in cardiovascular functions in patient with hypothyroidism. ${ }^{8}$ In patients with hypothyroidism, a true enhanced incidence of hypertension has been found. The reported prevalence of hypertension in hypothyroidism varies between $0 \%$ and $50 \%$. Hypothyroidism has been identified as a cause of hypertension in $3 \%$ of patients with high blood pressure. Patient 


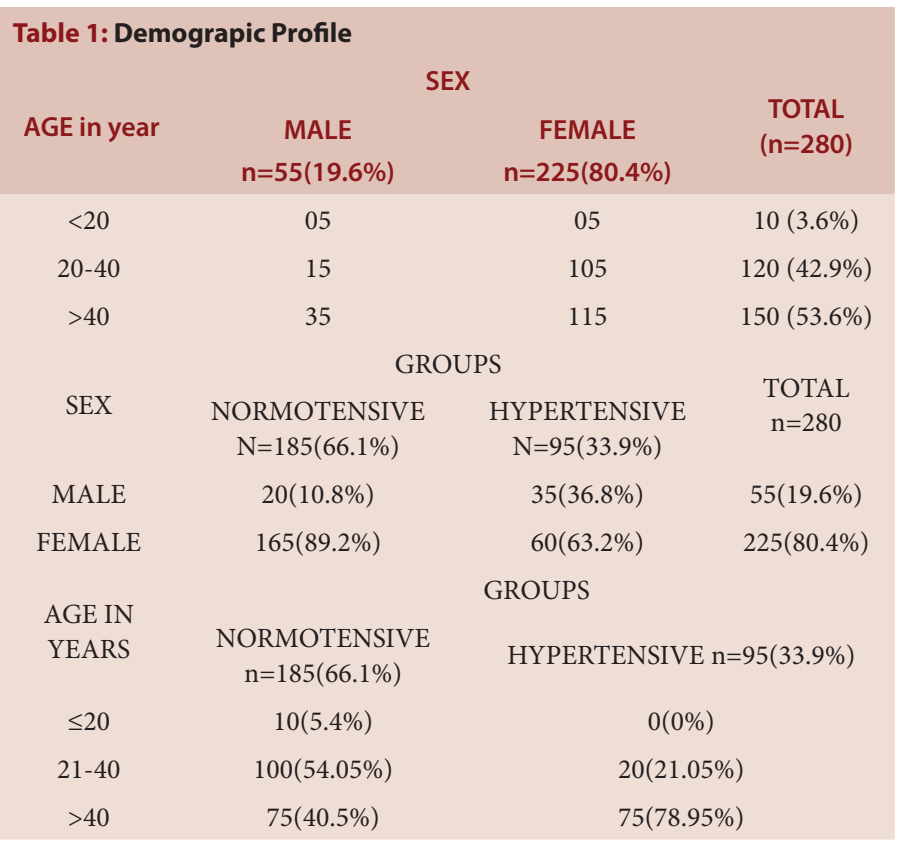

\begin{tabular}{|ccccc|}
\multicolumn{5}{c}{ Table 2: Distribution of TSH Levels with Grade of Hypertension } \\
$\begin{array}{c}\text { TSH LEVEL IN } \\
\text { mIU/I }\end{array}$ & $5-6.5$ & $6.6-8.5$ & $8.6-10$ & TOTAL CASES \\
STAGE1 & $05(8.33 \%)$ & $30(50 \%)$ & $25(41.66 \%)$ & $60(63.15 \%)$ \\
STAGE 2 & $00(0 \%)$ & $20(57.14 \%)$ & $15(42.86 \%)$ & $35(36.85 \%)$ \\
\hline
\end{tabular}

Pearson chi $2=5.5412 \quad \mathrm{p}=0.0236$

\begin{tabular}{|c|c|c|c|}
\hline & $\begin{array}{l}\text { Normotensive } \\
\text { Group } \\
\mathrm{N}=185(66.1 \%)\end{array}$ & $\begin{array}{c}\text { Hypertensive } \\
\text { Group } \\
\mathrm{N}=95(33.9 \%)\end{array}$ & $P$ value \\
\hline Sex $(M: F)$ & 20: 165 & $35: 60$ & $<0.001$ \\
\hline Age (Years) & $38.32 \pm 12.4$ & $48.0 \pm 12.7$ & $<0.001$ \\
\hline $\begin{array}{l}\text { Family history of } \\
\text { hypertension }\end{array}$ & $10 / 185(5.4 \%)$ & $15 / 95(15.7 \%)$ & $<0.001$ \\
\hline Weight (kg) & $59.3 \pm 8.4$ & $65.1 \pm 6.7$ & $<0.001$ \\
\hline BMI $\left(\mathrm{kg} / \mathrm{m}^{2}\right)$ & $22.3 \pm 7.2$ & $23.8 \pm 8.2$ & NS \\
\hline Smoking & $13(7 \%)$ & $19(20 \%)$ & $<0.001$ \\
\hline Diabetes & $14(7.5 \%)$ & $8(8.4 \%)$ & NS \\
\hline
\end{tabular}

Table 5: Effect of thyroxine replacement on systolic, diastolic, mean BP and Weight reduction in hypertensive patients

\begin{tabular}{ccccc} 
MONTH & $\begin{array}{c}\text { SBP } \\
\text { MEAN } \pm \text { SD }\end{array}$ & $\begin{array}{c}\text { DBP } \\
\text { MEAN } \pm \text { SD }\end{array}$ & $\begin{array}{c}\text { MEAN } \\
\text { BP } \pm S D\end{array}$ & $\begin{array}{c}\text { MEAN } \\
\text { WEIGHT } \pm S D\end{array}$ \\
\hline 0 & $145.4 \pm 14.9$ & $96.2 \pm 3.1$ & $112.3 \pm 6.4$ & $65.1 \pm 6.7$ \\
$11 / 2$ months & $136.3 \pm 12.8$ & $90.2 \pm 4.1$ & $106.5 \pm 7.2$ & $64.7 \pm 6.6$ \\
3RD & $129.7 \pm 7.3$ & $86.4 \pm 3.3$ & $100.7 \pm 2.9$ & $64.0 \pm 6.8$ \\
6TH & $125.3 \pm 4.6$ & $83.0 \pm 2.5$ & $97.1 \pm 1.8$ & $63.9 \pm 6.9$
\end{tabular}

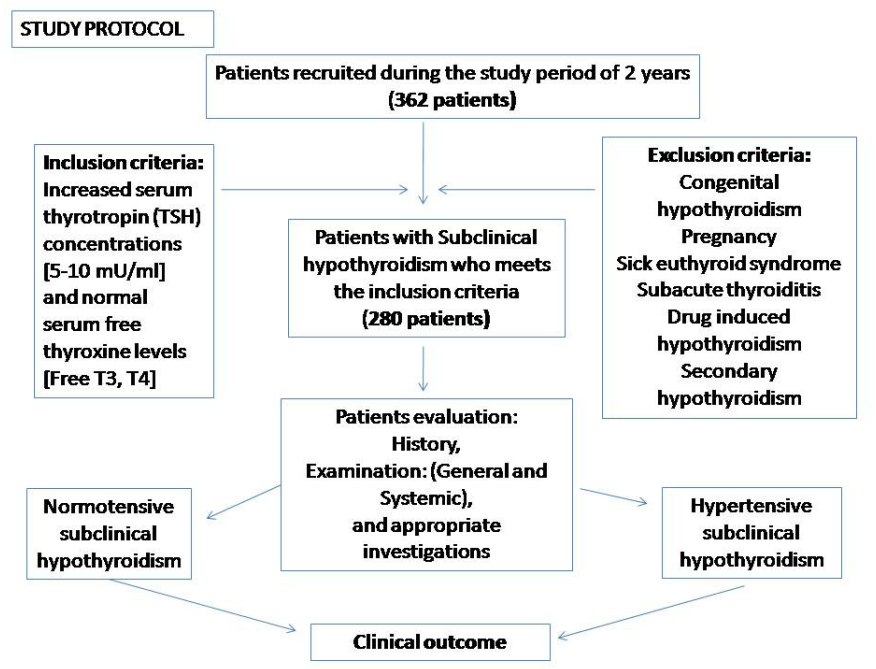

Figure 1: Study Protocol

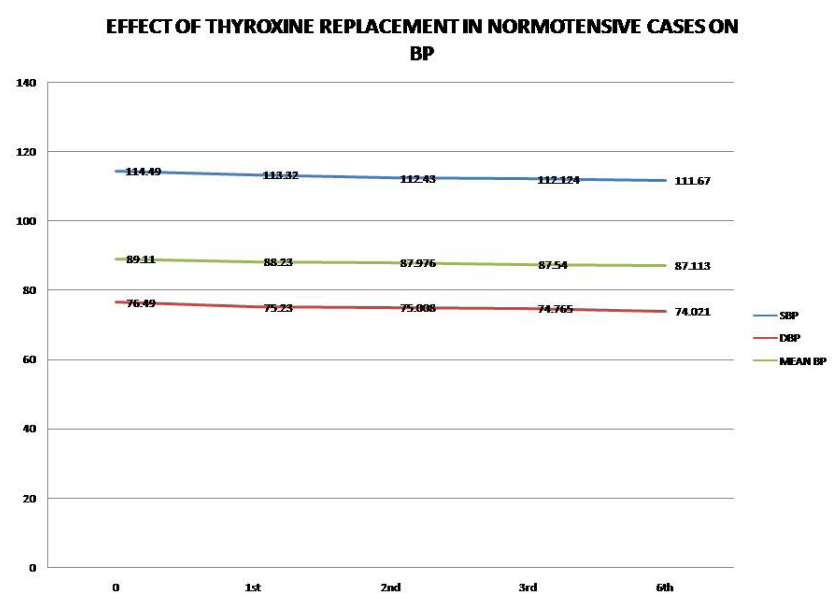

Figure 2: Effect of Thyroxine Replacement on Systolic, Diastolic and Mean BP In Cases of Normotension Patients With Subclinical Hypothyroidism

with hypothyroidism have a 3-fold increased prevalence of hypertension, usually diastolic. In addition, hypercholesterolemia and impairment of fatty acid mobilization are associated with myxedema and present additional risk factor for the development of atherosclerotic cardiovascular disease. ${ }^{9}$ 


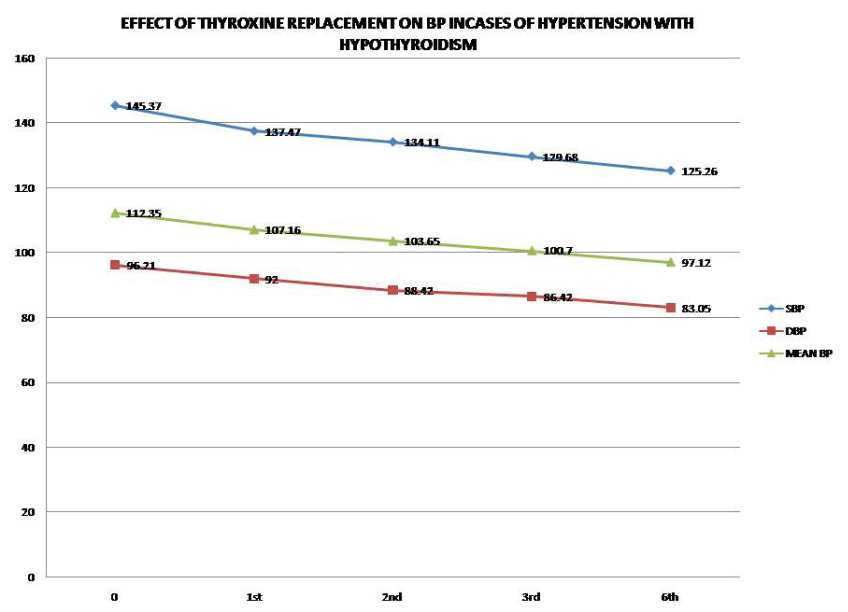

Figure 3: Effect of Thyroxine Replacement on Systolic, Diastolic And Mean BP In Cases of Hypertension Patients With Subclinical Hypothyroidism

These are two main factors contribute to systemic hypertension in subclinical hypothyroidism. The first and certainly the most widely recognized, is the remarkable increase in peripheral vascular resistance. The second and more recently documented is the increase in arterial stiffness, which likely results from myxedema of arterial wall. In general systemic hypertension associated with subclinical hypothyroidism is poorly controlled by conventional treatment, whereas it promptly improves with achievement of euthyroidism. So it is important to encourage the routine assessment of thyroid function in all patients with pre-existing systemic hypertension that became resistant to pharmacological treatment. ${ }^{10}$ Studies have shown that sub-clinical hypothyroidism has been associated with elevated diastolic BP, which also resolved after $\mathrm{T}_{4}$ treatment. ${ }^{11}$ Whether patients with sub-clinical hypothyroidism require $\mathrm{T}_{4}$ treatment remains controversial, but the risk of developing overt hypothyroidism especially in the presence of thyroid antibodies is high. Therefore, treatment of the condition may halt the progression to overt hypothyroidism. Sub-clinical hypothyroidism may leads to intrinsic myocardial changes, reflected by changes in contractility and relaxation, causing decreased cardiac contraction, cardiac output, heart rate, left ventricular compliance, and an increase in total peripheral resistance, which may be responsible for the observed hypertension. Other studies have however reported that cardiac structure and function remain normal in the sub-clinical hypothyroidism. ${ }^{12}$

In our study, we had found significant reduction of blood pressure on thyroid hormone replacement in hypertensive patient with subclinical hypothyroidism. The mean fall in blood pressure in normotensive patient was in systolic blood pressure, $2.72 \pm 3.2$ diastolic blood pressure $2.45 \pm 4.2$ and in mean arterial pressure $1.97 \pm 3.8$ after thyroxine replacement therapy while in cases of hypertension mean fall in blood pressure after thyroxine replacement therapy was in systolic blood pressure $20.1 \pm 11.2$ diastolic blood pressure 13.1 \pm 3.8 and in mean arterial pressure 15.1 \pm 4.7 without supplementing any antihypertensive therapy. The normalization of blood pressure in cases of hypertension with hypothyroidism with normalization of serum TSH level after thyroxine replacement therapy was significant $(<\mathrm{p}=0.05)$.

Responders to anti hypertensive treatment have been defined as any patient with a fall in mean arterial pressure, however small; any patient with a fall in mean arterial pressure of $5 \%, 10 \%$ or greater; and any patient achieving a goal blood pressure, usually a diastolic pressure less than $90 \mathrm{~mm} \mathrm{Hg}$.
Non-responders are normally defined as those who do not fit into the category of a responder. In our study, after 6 months of thyroxine replacement all the patients had more than $5 \%$ reduction in mean BP, and all achieved diastolic of less than $90 \mathrm{~mm} \mathrm{Hg}$, hence no nonreponders.

\section{CONCLUSION}

The effect of thyroid hormone replacement on blood pressure in cases of hypothyroidism is positively correlated i.e. on thyroid hormone replacement there is decrease in blood pressure in both systolic as well as diastolic after normalization of serum TSH level.

\section{CONFLICT OF INTEREST}

No potential conflict of interest relevant to this article was reported.

\section{ACKNOWLEDGEMENT}

On behalf of all the contributors I will act and guarantor and will correspond with the journal from this point onward.

\section{ABBREVIATION USED}

SCH: Subclinical hypothyroidism; TSH: Thyroid Stimulating Hormone; CIMT: Carotid Intima-Media Thickness; BP: Blood Pressure; SBP: Systolic blood pressure; BMI: Body Mass Index.

\section{REFERENCES}

1. Devdhar M, Ousman YH, Burman KD. Hypothyroidism. Endocrinol Metab Clin North Am. 2007;36(3):595-615.

2. Boucai L, Hollowell JG, Surks MI. An approach for development of age-, gender-, and ethnicity-specific thyrotropin reference limits. Thyroid. 2011;21(1):5-11.

3. Stabouli S, Papakatsika S, Kotsis V. Hypothyroidism and hypertension. Expert Rev Cardiovasc Ther. 2010;8(11):1559-65.

4. Walsh JP, Bremner AP, Bulsara MK, O'Leary P, Leedman PJ, Feddema P, et al. Subclinical thyroid dysfunction as a risk factor for cardiovascular disease. Arch Intern Med. 2005;165(21):2467-72.

5. Imaizumi M, Akahoshi M, Ichimaru S, Nakashima E, Hida A, Soda M, et al. Risk for ischemic heart disease and all-cause mortality in subclinical hypothyroidism. J Clin Endocrinol Metab. 2004;89(7):3365-70.

6. Schultz M, Kistorp C, Raymond I, Dimsits J, Tuxen C, Hildebrandt P, et al. Cardiovascular events in thyroid disease: A population based, prospective study. Horm Metab Res. 2011;43(9):653-9.

7. Gumieniak O, Perlstein TS, Hopkins PN, Brown NJ, Murphey LJ, Jeunemaitre $X$, et al. Thyroid function and blood pressure homeostasis in euthyroid subjects. J Clin Endocrinol Metab. 2004;89(7):3455-61.

8. Agarwal P, Singh MM, Gutch M. Thyroid function and metabolic syndrome Thyroid Res Pract. 2015;12(3):85-6.

9. Saltiki K, Voidonikola P, Stamatelopoulos K, Mantzou E, Papamichael C, Alevizaki M. Association of thyroid function with arterial pressure in normotensive and hypertensive euthyroid individuals: A cross-sectional study. Thyroid Res. 2008;1(1):3.

10. Liu D, Jiang F, Shan Z, et al. A cross-sectional survey of relationship between serum TSH level and blood pressure. J Hum Hypertens. 2010;24(2):134-8.

11. Kahaly GJ, Dillmann WH. Thyroid hormone action in the heart. Endocr Rev. 2005;26(5):704-28.

12. Owen PJ, Rajiv C, Vinereanu D, Mathew T, Fraser AG, Lazarus JH. Subclinical hypothyroidism, arterial stiffness, and myocardial reserve. J Clin Endocrinol Metab. 2006;91(6):2126-32

13. Tunbridge WM, Evered DC, Hall R, Appleton D, Brewis M, Clark F, et al. Lipid profiles and cardiovascular disease in the Whickham area with particular reference to thyroid failure. Clin Endocrinol (Oxf). 1977;7(6):495-508.

14. Sanjay S, Bharti GS, Manish G, Rajeev P, Pankaj A, Puspalata A, et al. Metabolic syndrome: An independent risk factor for erectile dysfunction. Indian J Endocr Metab. 2015;19(2):277-82

15. Parle JV, Franklin JA, Cross KW, Jones SR, Sheppard MC. Circulating lipids and minor abnormalities of thyroid function. Clin Endocrinol (Oxf). 1992;37(5):411-4.

16. Geul KW, Van Sluisveld IL, Grobbee DE, Docter R, De Bruyn AM, Hooykaas H, et al. The importance of thyroid microsomal antibodies in the development of elevated serum TSH in middle-aged women: association with serum lipids. Clin Endocrinol (Oxf). 1993;39(3):275-80.

17. Imaizumi M, Akahoshi M, Ichimaru S, Nakashima E, Hida A, Soda M, et al. Risk for ischemic heart disease and all-cause mortality in subclinical hypothyroidism. 
J Clin Endocrinol Metab. 2004;89(7):3365-70.

18. Hak AE, Pols HA, Visser T, Drexhage HA, Hofman A, Witteman JC. Subclinical hypothyroidism is an independent risk factor for atherosclerosis and myocardial infarction in elderly women: the Rotterdam study. Ann Intern Med. 2000; 132(4):270-8.

19. Monzani F, Caraccio N, Korakowa M, Dardano A, Vittone F, Virdis A, et al. Effect of levothyroxine replacement on lipid profile and intima-media thickness in subclinical hypothyroidism: a double- -blind, placebo-controlled study. J Clin Endocrinol Metabol. 2004;89(5):2099-106

20. Nagasaki T, Inaba M, Yamada S, Shirakawa $K$, Nagata $Y$, Kumeda $Y$, et al. Decrease of brachial-ankle pulse wave velocity in female subclinical hypothyroid patients during normalization of thyroid function: a double-blind, placebo-controlled study. Eur J Endocrin. 2009;160(3):409-15.
21. Kim SK, Kim SH, Park KS, Park SW, Cho YW. Regression of the Increased Common Carotid Artery-intima Media Thickness in Subclinical Hypothyroidism after Thyroid Hormone Replacement. Endocr J. 2009;56(6):753-8.

22. Duan Y, Peng W, Wang X, Tang W, Liu X, Xu S et al. Community-based study of the association of subclinical thyroid dysfunction with blood pressure. Endocrine. 2009;35(2):136-42.

23. Liu D, Jiang F, Shan Z, Wang B, Wang J, Lai Y, et al. A cross-sectional survey of relationship between serum TSH level and blood pressure. J Hum Hypertens. 2010;24(2):134-8.

24. Walsh JP, Bremner AP, Bulsara MK, O'Leary P, Leedman PJ, Feddema P et al Subclinical thyroid dysfunction and blood pressure: a community-based study. Clin Endocrinol (Oxf). 2006;65(4):486-91.

Cite this article : Kumar S, Rungta S, Gutch M, Bhattacharya A, Razi SM, Avinash A. The Effect of Thyroid Hormone Replacement on the Level of Blood Pressure in the Cases of Subclinical Hypothyroidism. Int J Med Public Health. 2018;8(1):24-28. 